\title{
Gestão da educação na perspectiva dos Direitos Humanos: garantias de possibilidades
}

\author{
Education management in the perspective of Human \\ Rights: guarantees of possibilities
}

\section{Gestión de la educación en la perspectiva de Derechos Humanos: garantías de posibilidades}

\section{Naura Syria Carapeto Ferreira*}

\section{Resumo}

Este artigo examina a relação, responsabilidades, garantias e possibilidades da gestão da educação na perspectiva dos Direitos Humanos. Defende a educação enquanto direito inalienável de todo o ser humano, acompanha aquele desde quando concebidos, pois faz parte da constituição humana o direito a todas as possibilidades que lhe são inerentes. Tal defesa se firma, igualmente, na compreensão de que a sociedade, assim como o ser humano, é sempre unidade histórica, que se desenvolve mediante a contínua superação em unidade dialética. Disso resulta uma reconstrução coletiva e contínua dos diretos humanos como fundamento do respeito e da dignidade humana. Na medida em que essa

* NSCF: Doutora em educação, e-mail: nauraf@uol.com.br 
compreensão vai sendo explicitada e compreendida, esboçando-se no espírito ideia de universalidade e indivisibilidade dos direitos humanos, que não aceita qualquer divisão de direitos por se tratar da pessoa humana, abre-se o caminho para examinarmos e defendermos a educação como um direito social básico a todas as pessoas. Os direitos humanos passam a ser tratados na sua totalidade, mas sob o enfoque da especificidade da educação, pela ideia de mediação da origem do homem e de sua constituição humana e histórica com direito a todas as possibilidades que lhes confere dignidade humana. Se a educação é mediação, responsável pela formação humana. Necessário se faz compreender que direitos tem essa pessoa humana e como a gestão da educação responsabiliza-se concomitantemente com os Direitos Humanos por essa formação e garantia de seus direitos.

Palavras-chave: Gestão da Educação. Direitos Humanos. Formação Humana. Dignidade.

\section{Abstract}

This paper examines the relationship, responsibilities, guarantees and possibilities of education management from the perspective of Human Rights. It advocates education as an inalienable right of every human being, following since conception, thus it is part of the human constitution the right to all the possibilities that are inherent. Such defense is based on the understanding that the society, such as the human being, is always a historical unit, which develops through the continuous overcoming in dialectical unity. This results in a collective and continuous reconstruction of human rights as the foundation of respect and human dignity. To the extent that this understanding is being explained and understood, outlining in the spirit idea of universality and indivisibility of human rights, which does not accept any rights division because it is the human person, it opens the way to examine and defend the education as a basic social right to all people. Human rights come to be treated in their entirety, but in the education specificity of the approach, through idea of mediation of the origin of man and his human and historical constitution entitled to all the possibilities that gives them human dignity. If education is mediation, responsible for human development, it is necessary to understand what rights this human person has and 
as the management of education is responsible concomitantly with Human Rights for such formation and guarantee of their rights.

Keywords: Education Management. Human rights. Human formation. Dignity.

\section{Resumen}

Este artículo examina la relación, responsabilidades, garantías y posibilidades de gestión de la educación desde la perspectiva de los derechos humanos. Aboga por la educación como un derecho inalienable de todo ser humano, como parte de la constitución humana el derecho de todas las posibilidades que le son inherentes. Esta defensa es firme, también, en el entendimiento de que la sociedad, así como el ser humano, es siempre la unidad histórica, que se desarrolla a través de la superación continua en la unidad dialéctica. Esto da lugar a una reconstrucción colectiva y continua de los derechos humanos como la base del respeto y la dignidad humana. En la medida en que esta comprensión se explica y se entiende, está indicando la idea de universalidad e indivisibilidad de los derechos humanos, que no se hace la división de derechos, ya que es la persona humana, que abre el camino para examinar y defender la educación como un derecho social básico para todas las personas. Los derechos humanos llegan a ser tratados en su totalidad, sino en la especificidad de la educación del enfoque, la idea de la mediación del origen del hombre y su constitución humana e histórica con derecho a todas las posibilidades que les da la dignidad humana. Si la educación es la mediación, responsable de desarrollo humano. Necesita entender cuáles son sus derechos a esta persona humana y la gestión responsable de la educación de forma concomitante con los Derechos Humanos para dicha formación y garantizar sus derechos.

Palabras clave: Gestión de la Educación. Derechos humanos. Formación humana. Dignidad. 


\section{Introdução}

A expressão "direitos humanos" é uma forma abreviada de mencionar os direitos fundamentais da pessoa humana. Esses diretos são considerados fundamentais porque sem eles a pessoa humana não consegue existir ou não é capaz de se desenvolver ou participar plenamente da vida. Todos os seres humanos devem ter assegurados, desde o nascimento, as condições mínimas necessárias para se tornarem úteis à sociedade, como também devem ter a possibilidade de receber os benefícios que a vida em sociedade pode proporcionar. Esse conjunto de condições e de possibilidades associa as características naturais dos seres humanos, a capacidade natural de cada pessoa e os meios que a pessoa pode valer-se como resultado da organização social. [...] Para entendermos com facilidade o que significam direitos humanos, basta dizer que tais direitos correspondem a necessidades essenciais da pessoa humana (DALLARI, 1998, p. 7).

Sirvo-me desta reflexão de Dallari (1998) para refletir sobre o tema Gestão da Educação e Direitos Humanos, especialmente por defender, os Direitos Humanos sendo "considerados fundamentais porque sem eles a pessoa humana não consegue existir ou não é capaz de se desenvolver ou participar plenamente da vida". Se tal é um pré-requisito no raciocínio do eminente professor catedrático da UNESCO na cadeira de Educação para a Paz, Direitos Humanos, Democracia e Tolerância - criada na Universidade de São Paulo - , cabe examinar a educação e sua gestão à luz dos Direitos Humanos. Entendo desta forma, vista que a educação ocupa lugar de destaque na constituição da República Federativa do Brasil que, no Capítulo II, Art. $6^{\circ}$ exara "São direitos sociais a educação, a saúde, a alimentação, o trabalho, a moradia, o transporte, o lazer, a segurança, a previdência social, a proteção à maternidade e à infância, a assistência aos desamparados, na forma desta Constituição" (BRASIL, 1988). Redação dada pela Emenda Constitucional n 90, de 2015). Temse, portanto, determinado pela Carta Magna do Brasil que a educação é 
um direito social que deve ser cumprido em relação a todos os brasileiros e nunca desrespeitado.

O inconteste vínculo entre a educação, na Constituição da República Federativa do Brasil (CFRB), com os Direitos Humanos é fator determinante de que só é possível se realizar a educação, em nossa nação, destinada a todos os seres humanos nos termos desta legislação e desse vínculo.

Afirma ainda Dallari (1998, p.7), na assertiva acima, "todos os seres humanos devem ter assegurados, desde o nascimento, as condições mínimas necessárias para se tornarem úteis à sociedade, como também devem ter a possibilidade de receber os benefícios que a vida em sociedade pode proporcionar". Tem-se a ratificação da necessidade de a educação ser considerada como um direito, condição indispensável à vida plena na sociedade. Entendo e defendo, portanto, a formação humana de toda a população brasileira com o maior rigor possível no sentido da formação plena para a cidadania. Como escrevi em outro lugar:

Falo de uma aprendizagem de conteúdos de vida que abrangem os conceitos científicos da cultura erudita e os conteúdos éticos da convivência social. Esse rigor é o maior humanismo que se poder exigir de todos os profissionais da educação, a fim de que os alunos e alunas, homens e mulheres, profissionais da educação e profissionais em geral possam desenvolver-se como seres humanos fortes intelectualmente, ajustados emocionalmente, capazes tecnicamente e ricos de caráter (FERREIRA, 2013, p. 138).

Também a Lei 9.294/1996, de 20 de dezembro de 1996 especifica no seu artigo $2^{\circ}$ que "A educação, dever da família e do Estado, inspirada nos princípios de liberdade e nos ideais de solidariedade humana, tem por finalidade o pleno desenvolvimento do educando, seu preparo para o exercício da cidadania e sua qualificação para o trabalho" (BRASIL, 1996). Mais uma determinação legal, política, ética e humana se expressa no "preparo para o exercício da cidadania e sua qualificação para o trabalho". Esta falando de rigor, de cidadania plena, de educação para todos 
com a qualidade de pensamento necessária à vida em sociedade como sujeitos históricos. Isto é direito a Educação na perspectiva dos Direitos Humanos. Entretanto, se faz necessário prosseguir com algumas compreensões de fundo.

Muito tem-se escrito sobre Direitos Humanos e muito se escreve também sobre gestão da educação, mas não se assegura que o que está exarado na Constituição (1988) de um país, como no Brasil, os direitos sejam assegurados e garantidos e, muito menos, criando as possibilidades para que isto aconteça. O que consta em nossa CFRB é exatamente o que corresponde aos Direitos Humanos, que necessitam ser respeitados e cumpridos, especialmente por se tratar "da possibilidade de receber os benefícios que a vida em sociedade pode proporcionar" (BRASIL, 1988). Se a educação é mediação, responsável pela formação humana, se faz necessário compreender que direitos têm essa pessoa humana e como a gestão da educação responsabiliza-se concomitantemente com os Direitos Humanos por essa formação e a garantia desses direitos. Ambos os termos significam responsabilidade pelo direito e qualidade da formação humana a todos os humanos, enquanto direito inalienável de todos.

Compreende-se o ser humano como "conjunto das relações sociais", como sujeito histórico, cuja atividade é criar, por meio de seus atos, a história, criando consequentemente, a história da humanidade. Isso consiste em tomar como ponto de partida os indivíduos reais, concretos, que produzem dentro da sociedade em condições concretas, com direito de poder fruir de suas produções, de toda a produção da cultura. Somente dessa forma, compreende-se a constituição humana, que através da educação - como direito social - se hominiza, como ser liberto, orgânico, emancipado, lúcido, no sentido de sua formação e integral realização humana, enquanto humaniza a sociedade. Todavia, não se consegue viabilizar tal compreensão e intento apenas pela via da instrumentalização do conhecimento científico, na aceitação generalizada da "formação para a cidadania" numa sociedade minada pela ideologia hegemônica do individualismo, egoísmo, competitividade, consumismo, que produz ódio entre os humanos, e a sua consequente coisificação. Tal espírito infiltra 
de forma qualitativamente vigorosa, através do requinte das diversas formas de consciência social, permitindo reeditar, sob novas práticas, velhas concepções discricionárias, exclusivas e excludentes e, por isso, mortais!

Com Marx (1980, p.49), aprendemos que "não é a consciência que determina a realidade, mas a realidade que determina a consciência". Essa compreensão está alicerçada na defesa inconteste dos direitos humanos para todas as pessoas, sem discriminação de qualquer ordem, sendolhe conferidos exatamente por sua condição humana, como ser histórico, partícipe de uma determinada sociedade.

Tal defesa se firma igualmente na compreensão de que a sociedade, assim como o ser humano, é sempre e só uma unidade histórica, que se desenvolve mediante a contínua superação em uma unidade dialética. Disso resulta uma reconstrução coletiva e contínua dos diretos humanos como fundamento do respeito e da dignidade humana.

$\mathrm{Na}$ medida em que essa compreensão vai sendo explicitada e compreendida, na mesma via de raciocínio, esboçando-se no espírito/ ideia de universalidade e indivisibilidade dos direitos humanos, que não aceita qualquer divisão de direitos por se tratar da pessoa humana, abrese o caminho para examinarmos e defendermos a educação como um direito social básico a todas as pessoas, e a sua gestão como garantia da formação humana com todos os direitos que lhes são inerentes.

Gestão da Educação e políticas públicas de formação de profissionais da educação constituem-se em meu objeto de investigação por mais de quarenta anos, o que me leva a ter sólidas convicções e responsabilidades quanto ao que escrevo, digo e/ou faço, assim como a humildade de avaliar o que escrevo, digo e/ou faço.

A formação humana se constitui a partir da responsabilidade de um conjunto de tomadas de decisões por parte dos dirigentes da educação que gestam e supervisionam a educação a ser realizada e, em sua execução a partir de princípios que norteiam esta ação. É, portanto, a Gestão da Educação entendida em sua complexa totalidade como o conjunto de processos que se realizam para a execução de determinados fins, sem o que a formação humana não ocorreria. 
Define-se, então Gestão da educação como tomada de decisões! Decisões de sujeitos conscientes e responsáveis, num contexto dado e de uma determinada forma, mediante princípios, valores e necessidades reais! Decisões estas, que são tomadas entre alternativas que existem ou que se criam numa realidade concreta! Tais decisões são tomadas por seres humanos de "carne e osso", pensamento e sentimento. Sujeitos históricos em uma realidade também histórica com suas determinações, especificidades e contradições, que agem de forma objetiva e prática, tendo em vista a consecução de próprios fins e interesses, dentro de um determinado conjunto de relações sociais. Assim se processa a necessidade da garantia de sua execução para a formação em notas as dimensões, de todos os seres humanos.

Sabe-se que toda a tomada de decisão é política, pois, é a partir de uma fixação de prioridades, ou valores que se tomam decisões que sempre serão políticas, pois na compreensão de Ball (1990, p. 89-101), aqui assumida, "política consiste na fixação de valores constituindo declarações intencionais e operacionais".

Como afirmei no Pósfácio - A Supervisão Educacional no Contexto da Gestão da Educação: Por uma formação humana, da $16^{\mathrm{a}}$ edição do Livro Supervisão Educacional: uma reflexão crítica:

Pode-se pois compreender e afirmar que gestão e política são dois termos cujos conceitos se imbricam e se indissociam, pois sempre que existe política, por consequência faz-se necessário tomar decisões e, concomitantemente, em toda gestão existe uma intenção que define as tomadas de decisões necessária, tornando-se política. Tais tomadas de decisão podem querer atender interesses individuais ou interesses coletivos. (FERREIRA, 2007, p. 111)

Tem-se assim, o desafio de pensar as garantias e possibilidades da Gestão da educação na perspectiva dos direitos humanos para toda a população. Vejamos! 


\section{Direitos Humanos: garantias de possibilidades}

Parto do pressuposto de que os direitos humanos são valores desejáveis, isto é, fins que merecem ser perseguidos, e de que, apesar dessa "desejabilidade", não foram ainda todos (por toda a parte e em igual medida) reconhecidos; e estou convencida de que lhes encontrar um fundamento, ou seja, aduzir motivos para justificar a escolha que fizemos e que gostaríamos que fosse feita também pelos outros, é um meio adequado para obter para todos um mais amplo reconhecimento. Os direitos humanos, que foram sendo reconhecidos universalmente por meio da história, somente vieram a ser positivados no período pós Segunda Guerra Mundial - quando houve uma verdadeira barbárie e desrespeito a estes direitos e à dignidade da pessoa humana.

Nos dias atuais, de outras formas mais sofisticadas e, também, mais intensas e agressivas - ocasionadas pelo acirramento do capitalismo imperialista selvagem - esta barbárie se expressa com extrema violência através do terrorismo, da xenofobia, da corrupção desmedida, lesando mentes e corações no mundo globalizado. A consciência social do capitalismo espoliador que mina as mentes e corações da população que passa, a partir desta contaminação feita principalmente pela mídia, a ter um modo de viver também usurpador, mentiroso, enganador, avassalador e, portanto, violento.

A chamada "cultura globalizada" na atual etapa de desenvolvimento, apresenta características e demandas muito peculiares, contraditórias, complexas, em intensa quantidade. Atender, viver e produzir a existência, através do trabalho no mundo que se impõe com toda a sua evolução e, concomitantemente, com toda a violência, através da mídia em suas diversificadas, evoluídas e aceleradas formas constitui-se uma exigência que a educação e sua gestão necessitam assumir construindo e reconstruindo coletivamente uma política educacional viva que priorize o humano em todas as pessoas do mundo e no conjunto da humanidade. Cada vez mais se faz imperioso educar e reeducar-se continuamente, sob 
e nos ditames das exigências dessa "cultura globalizada" que invadiu todo o planeta e enquanto humanidade (FERREIRA, 2010, p. 23-25)

Os dias atuais apresentam uma "ordem" em que as "mídias" podem agora, em lugar de se precipitar sobre os acontecimentos, em lugar de criá-los, de empolá-los, imprimir-lhe sua incrível dinâmica e sua capacidade de distribuir alucinantes massas de informação. A contemporaneidade é fruto principalmente de uma ordem econômica capitalista mundial que envolve a formação de um tipo especial de Estado e de modo geral, de tipos de organização, os quais dependem fundamentalmente da estruturação da informação. Vale, aqui, aplicar a noção de "vigilância", emprestada de Foucault "para aludir ao modo como se constroem sistemas de informação visando constituir novos sistemas administrativos" (GIDDENS; PIERSON, 2.000, p. 74).

A partir do período pós Segunda Guerra Mundial, como já foi referido acima, quando houve uma verdadeira barbárie e desrespeito a estes direitos e à dignidade da pessoa humana, houve uma maior participação por parte dos Estados na tentativa de resgatar os direitos humanos, incluindo-os em suas Constituições e realizando uma declaração que pudesse vincular os países à obrigação de garantir estes direitos (Declaração Universal dos Direitos Humanos - 1948), numa tentativa de lhes dar maior efetividade e eficácia.

Percebe-se que, então, passou a haver maior participação por parte dos Estados na tentativa de resgatar os direitos humanos, incluindo -os em suas Constituições e realizando uma declaração que pudesse vincular os países à obrigação de garantir estes direitos (Declaração Universal dos Direitos Humanos), numa tentativa de lhes dar maior efetividade.

Os DH foram elencados como cláusulas pétreas em nossa Constituição da República Federativa do Brasil de 1988 - resultado de lutas travadas ao longo da história e que atingiram um patamar que não pode ser retrocedido, sob pena de atingir o princípio de proibição do retrocesso social.

Vale lembrar que os direitos humanos surgiram com a intenção de proteger e resguardar as necessidades da pessoa humana, por esta 
perceber direitos inerentes a si pela sua simples condição. São considerados os direitos do ser humano enquanto tal, inerentes à sua própria natureza, estando eles ligados ao direito natural e internacional.

Entretanto os Direitos Humanos passam a ser considerados direitos fundamentais a partir do momento em que são positivados pela ordem jurídica de determinado Estado, passando assim, a ter um grau maior de exigibilidade e respeito dentre as demais normas internas, sejam eles positivos ou negativos, ou seja, quer eles representem uma prestação ou uma abstenção por parte do Estado. E são os chamados direitos sociais que protegem não o homem como indivíduo unitário, mas na sua vida em sociedade, propiciando a realização de uma vida digna, com trabalho, saúde, educação, assistência social e segurança. Dentre estes direitos sociais, a educação é fundamental, assim como os outros o são mais prioritária no sentido do seu desenvolvimento à condição cidadã, isto, é à condição de ir e vir por conhecer e poder tomar decisões entre os caminhos possíveis e desejáveis. Significa tornar-se no "vir a ser" da jornada terrena, senhor do seu destino.

É necessário compreender, portanto, que os direitos fundamentais sociais correspondem a uma posição ativa do Estado, que se obriga a determinadas prestações, a fim de diminuir as desigualdades sociais, promovendo, dessa forma, a justiça social, possibilitando a cadê ser humano os direitos que lhes são devidos para que torne pleno como sujeitos histórico de sua vida e partícipe ativo de uma sociedade, com direitos plenos de poder intervir, reivindicar, decidir, participar, construir o mundo e a cultura em que vive. É poder tornar-se digno num contexto de vida que lhe é próprio através do pleno exercício de suas faculdades e condições necessárias para isso. A dignidade da pessoa humana é o fundamento dos direitos humanos.

O "Princípio da dignidade da pessoa humana" é um valor moral e espiritual inerente à pessoa, ou seja, todo ser humano é dotado desse preceito, e tal constitui o princípio máximo do Estado Democrático de Direito. 
Entendo que os direitos fundamentais constituem manifestações da dignidade da pessoa. Quando algum dos direitos fundamentais, qualquer que seja a família a que pertença, for violado é a dignidade da pessoa que sofre a ofensa, o que vem a se constituir numa violência. Como se explica partir das reflexões de Vazquez (1977) a respeito: a violência não é uma entidade metafísica e super-histórica; a violência está condicionada histórica e socialmente, quero dizer, são homens concretos que determinam o uso e o alcance da violência pelo conhecimento das determinações de uma situação contextualizada, seus elementos, possíveis consequências e possibilidades. Logo, as decisões que um ser humano toma, provém das possibilidades que ele teve de apropriação em todas as dimensões, dos elementos constitutivos de uma língua, cultura, "modos vivendi" e demais "instrumentos da vida", assim como das possibilidades que lhe permitam esta vida digna.

Os direitos fundamentais, portanto, asseguram as condições da dignidade e, não obstante a violação da norma, apesar da agressão, a dignidade estará preservada, porque ela é um valor intangível. A dignidade não se esgota nos direitos fundamentais, entretanto, só terá sua dignidade respeitada, o indivíduo cujos direitos fundamentais forem observados e realizados. Daí a importância do conhecimento dos Direitos Humanos pelo gestor da educação, a fim de que possa, enquanto dirigente de humanos em uma determinada situação profissional ou social, tomar decisões equânimes com a dignidade de todos.

Encontram-se, entre os fundamentos delineados na Constituição, a cidadania e a dignidade da pessoa humana. A dignidade da pessoa humana não é uma criação constitucional, pois ela é um desses conceitos a priori, um dado preexistente a toda experiência especulativa, tal como a própria pessoa humana. A Constituição da República Federativa do Brasil, reconhecendo a sua existência e a sua eminência, transforma - a dignidade - num valor supremo da ordem jurídica, quando a declara como um dos fundamentos da República Federativa do Brasil constituída em Estado Democrático de Direito. Os direitos fundamentais sociais revelam-se como exigência indistanciável do efetivo exercício das liberdades 
e garantia da igualdade de oportunidades, orientado pelo valor da justiça material.

Encontram-se entre os fundamentos delineados na Constituição a cidadania e a dignidade da pessoa humana elencados com destaque pela importância que têm na concepção de estado democrático de direito de nosso país. É, exatamente, o encontro dos direitos fundamentais e do princípio do Estado Democrático de Direito, que deixa indene de dúvidas que os direitos fundamentais constituem-se em elemento básico para a realização do princípio democrático, tendo em vista exercerem uma função democratizadora.

A superioridade da dignidade da pessoa humana é dotada ao mesmo tempo da natureza de valor supremo, princípio constitucional fundamental e geral que inspira a ordem jurídica. Mas, a Constituição lhe dá mais do que isso, quando a põe como fundamento da República Federativa do Brasil constituída em Estado Democrático de Direito. Se é fundamento é porque se constitui num valor supremo, num valor fundante da República, da Federação, do país, da democracia, do Direito, da Educação e da Gestão da Educação.

Não se trata apenas de um princípio da ordem jurídica, mas o é também da ordem política, social, econômica e cultural. Daí sua natureza de valor supremo, porque está na base de toda a vida nacional. E como tal tem legitimidade e deve ser respeitada por todos, principalmente pela educação se sua gestão democrática coadunada com o que reza a Carta Magna do Brasil.

Os direitos fundamentais foram os primeiros a serem reconhecidos pelas ordens jurídicas, com base no pensamento liberal-burguês do século XVIII, que marcaram o início da positivação das reivindicações burguesas nas primeiras constituições escritas do mundo ocidental. Representam direitos que os cidadãos possuem frente ao Estado, ou seja, trata-se de uma limitação ao poder do Estado em face do indivíduo. São os chamados direitos de liberdade, de cunho individual, significando uma abstenção por parte do Estado, diante dos direitos individuais 
dos cidadãos. Tratam-se dos direitos civis e políticos, incluídos o direito à vida, à liberdade, à propriedade e à igualdade perante a lei.

A Carta Constitucional de 1988 incorporou significativos avanços no campo dos direitos humanos, tanto os individuais como os difusos e coletivos, trazendo, inclusive, diversos "remédios constitucionais" para garantir a eficácia desses direitos. Necessário se faz o cumprimento desses direitos que retratam naquela Carta a feição do cidadão brasileiro pleno. E é este cidadão pleno com educação plena em todas as dimensões que a gestão democrática da educação necessita garantir "à luz" dos Direitos Humanos aqui expostos e defendidos.

Os direitos sociais, pela primeira vez na história constitucional brasileira, vieram elencados no capítulo destinado aos Direitos e Garantias Fundamentais, reconhecendo-os como tais, com o intuito de promover a igualdade material. Antes dos Direitos e Garantias Fundamentais, a Carta Magna definiu princípios fundamentais a servirem de fundamento ao Estado Democrático de Direito, como a cidadania, a dignidade da pessoa humana, os valores sociais do trabalho e a livre iniciativa, entre outros como está exarado no art. $1^{\circ}$, da Constituição da República Federativa do Brasil.

Assim, também, no artigo $3^{\mathrm{a}}$ enumerou os objetivos fundamentais da República, como sendo: "construir uma sociedade livre, justa e solidária; garantir o desenvolvimento nacional; erradicar a pobreza e a marginalização e reduzir as desigualdades sociais e regionais; promover o bem de todos, sem preconceito de origem, raça, sexo, cor, idade e quaisquer outras formas de discriminação". Trata de delinear os Direitos e Garantias Fundamentais aí incluídos os direitos individuais e coletivos e os direitos sociais que devem ser obedecidos regiamente pelos cidadãos brasileiros, todos, principalmente os que educam e tomam decisões sobre a qualidade, o conteúdo, as políticas intencionais e operacionais que ocorrem na escola.

Os direitos fundamentais sociais, portanto, representam prestações positivas estatais, enunciadas em normas constitucionais, que possibilitam melhores condições de vida aos menos favorecidos, na 
tentativa de realização da igualização de situações desiguais. São considerados pressupostos de gozo dos direitos individuais, na medida em que criam condições materiais mais favoráveis à obtenção da igualdade real. Proporcionando condição mais compatível com o exercício efetivo da liberdade.

Os direitos sociais, além de outros esparsos na Constituição, estão ainda previstos nos artigos $6^{\circ}$ a $11^{\circ}$ da CRFB. Aqui podemos encontrar os direitos sociais relativos ao trabalhador; direitos sociais relativos à seguridade, compreendendo os direitos à saúde, à previdência e à assistência social; direitos sociais relativos à educação e à cultura; direitos sociais relativos à família, criança, adolescente e idoso; direitos sociais relativos ao meio ambiente.

Importante salientar que além dos direitos à educação, à saúde, ao trabalho, ao lazer, à previdência social, à proteção à maternidade e à infância, à assistência aos desamparados, previstos originalmente, a Emenda Constitucional $\mathrm{n}^{\circ}$ 26, de 14.02.2000 acrescentou o direito à moradia ao rol dos direitos sociais consagrados no art. $6^{\circ}$ da CRFB. $O$ art. $7^{\circ}$ foi dedicado aos direitos especificamente dos trabalhadores, alargando em muito o rol desses direitos previstos nas Constituições anteriores. Estendeu, também, muitos desses direitos aos empregados domésticos, bem como a sua integração à previdência social.

Mas por que examinar, para o pleno exercício da gestão democrática da educação de qualidade, estes outros direitos? Porque fazem parte de uma mesma concepção de homem, mundo e sociedade que rege as políticas exaradas na, e a partir da, Constituição da República Federativa do Brasil.

Assim pode-se afirmar que os direitos sociais constituem direitos fundamentais e nessa esteira devem ser considerados como valores de uma sociedade. São considerados os direitos do ser humano enquanto tal, inerentes à sua própria natureza, estando eles ligados ao direito natural e internacional.

A dignidade da pessoa humana é o fundamento dos direitos humanos. Os direitos fundamentais constituem manifestações da dignidade 
da pessoa. Quando algum dos direitos fundamentais, qualquer que seja a família a que pertença, for violado, é a dignidade da pessoa que sofre a ofensa. Os direitos fundamentais asseguram as condições da dignidade e, não obstante a violação da norma, apesar da agressão, a dignidade estará preservada, porque ela é um valor intangível. A dignidade não se esgota nos direitos fundamentais, entretanto, só terá sua dignidade respeitada o indivíduo cujos direitos fundamentais forem observados e realizados.

Além dos direitos à educação, à saúde, ao trabalho, ao lazer, à previdência social, à proteção à maternidade e à infância, à assistência aos desamparados, previstos originalmente, a Emenda Constitucional $n^{\circ}$ 26/2000 (BRASIL, 2000), acrescentou o direito à moradia ao rol dos direitos sociais consagrados no art. $6^{\circ}$ : "São direitos sociais a educação, a saúde, a alimentação, o trabalho, a moradia, o transporte, o lazer, a segurança, a previdência social, a proteção à maternidade e à infância, a assistência aos desamparados, na forma desta Constituição". (Redação dada pela Emenda Constitucional no 90/2015) (BRASIL, 2015).

"Em obediência aos princípios fundamentais que emergem do Título I da Lei Maior, faz-se mister, em boa doutrina, interpretar a garantia dos direitos sociais como cláusula pétrea e matéria que requer, ao mesmo passo, um entendimento adequado dos direitos e garantias individuais do art. 60. Em outras palavras, pelos seus vínculos principiais já expostos - e foram tantos na sua liquidez inatacável - os direitos sociais recebem em nosso direito constitucional positivo uma garantia tão elevada e reforçada que lhes faz legítima a inserção no mesmo âmbito conceitual da expressão direitos e garantias individuais do art. 60... Os direitos sociais estão vinculados ao princípio constitucional da dignidade da pessoa humana".

Mas todos os cidadãos têm a mesma concepção de, mundo, de homem e de sociedade? Não! Por existir pluralidade de concepções que se torna imprescindível a unidade na interpretação. O princípio da unidade é uma especificação da interpretação sistemática, e impõe ao intérprete o dever de harmonizar as tensões e contradições entre normas. Deverá fazê-lo guiado pela grande bússola da interpretação constitucional: os 
princípios fundamentais, gerais e setoriais inscritos ou decorrentes da Lei Maior. Os princípios constitucionais se constituem na síntese dos valores mais relevantes da ordem jurídica, indicando o ponto de partida e os caminhos a serem percorridos. Os princípios se irradiam por todo o sistema normativo, repercutindo sobre outras normas constitucionais e a partir daí difundindo-se para as normas infraconstitucionais. Estes possuem uma função integradora e hermenêutica, na medida em que servem de parâmetro para aplicação, interpretação e integração de todo o ordenamento jurídico.

\section{Considerações finais: Finalizando para sempre recomeçar}

As garantias de possibilidades da gestão da educação na perspectiva dos Direitos Humanos residem numa interpretação da CRFB que atente à democracia social, na gestão da educação em consonância com os Direitos Humanos. E, necessita ser aquela que tenha por base a superioridade dos valores e princípios constitucionais, principalmente os valores da dignidade da pessoa humana. A interpretação constitucional tem como finalidade eleger a solução mais adequada e justa para o caso concreto, do ponto de vista dos princípios e direitos fundamentais recepcionados no texto constitucional, os quais se constituem em padrões para a aplicação do direito.

A importância deste "solo democrático" nasce do caráter contraditório que o acompanha: nele sempre reside uma dimensão de luta:

- Luta por inscrições mais democráticas.

- Luta por efetivações mais realistas.

- Lutas por descaracterizações mutiladoras

- Lutas por sonhos de justiça.

As precárias condições de existência social, preconceitos, discriminação de toda ordem, do antagonismo econômico e social, fundamentalismo, xenofobia, violência, terrorismo fomentam o ódio, a morte! Tais 
precárias determinações sociais exigem a efetivação de uma educação de qualidade, positivada na qualidade da formação para a cidadania, com:

1) sólidos saberes teóricos,

2) excelentes saberes tecnológicos e práticos,

3) significativa consciência social,

4) sólida formação de caráter,

5) condições dignas e materiais de trabalho,

6) respeito.

Reitero o que escrevi no Memorial defendido no concurso para Professor Titular da Universidade Tuiuti do Paraná (FERREIRA, 2002, p. 99): "Na nova etapa de vida que se inicia a cada momento, para mim, quero empreender, pensando, refletindo, sem nunca deixar de sonhar". Sonho com um mundo mais humano, com uma sociedade mais digna e justa, com uma escola de qualidade para todos e com profissionais da educação qualificados, respeitados e felizes. Sonho com uma escola e com uma universidade unitária e universal. Sonho com um mundo repleto de jardins onde floresçam rosas perfumadas sem espinhos, jardins repletos de crianças alegres as quais brincam aprendendo os conteúdos da vida. Não os conteúdos desta vida que estamos vivendo, mas os de uma vida que possua todos os meios e recursos para o bem da humanidade, dignamente à disposição de toda a humanidade.

Enfim, sonho com a pedagogia da esperança formada pela tolerância, o respeito e a solidariedade; uma pedagogia que rechaça a construção social de imagens que desumanizam o "outro"; uma pedagogia de esperança que ensina e vivencia que, ao construir o "outro", tornamo-nos completamente relacionados ao "outro"; uma pedagogia que ensina que ao desumanizarmos o "outro", desumanizamos a nós mesmos. Sonho com uma pedagogia da esperança que nos guie ao crítico caminho da verdade rumo a reapropriação da dignidade humana. 


\section{Referências}

BALL, S. Politics and policy making in education: explorations in policy. Londres: Routledge, 1990.

BRASIL. Constituição da República Federativa do Brasil de 1988. Emendas constitucionais. Brasília, DF. Disponível em: <http://www.planalto.gov.br/ccivil_03/ Constituicao/Constituicao.htm>. Acesso em: 20 set. 2016.

BRASIL, Lei $\mathrm{n}^{\circ}$. 9.394, de 20 de dezembro de 1996. Estabelece as Diretrizes e Bases da Educação Nacional. Diário Oficial da União, Brasília, DF 23 dez. 1996. Disponível em: <http://www.planalto.gov.br/ccivil_03/leis/L9394.htm>. Acesso em: 20 set. 2016.

BRASIL. Emenda constitucional no 26, de 14 de fevereiro de 2000. Altera a redação do art. $6^{\circ}$ da Constituição Federal. Diário Oficial da União, Brasília, DF, 15 fev. 2016. Disponível em: <http://www.planalto.gov.br/ccivil_03/constituicao/ emendas/emc/emc90.htm>. Acesso em: 20 set. 2016.

BRASIL. Emenda constitucional no 90, de 15 de setembro de 2015. Dá nova redação ao art. $6^{\circ}$ da constituição federal, para introduzir o transporte como direito social. Diário Oficial da União, Brasília, DF, 16 set. 2016. Disponível em: <http:// www.planalto.gov.br/ccivil_03/constituicao/emendas/emc/emc90.htm〉. Acesso em: 20 set. 2016.

DALLARI, D. Direitos humanos e cidadania. São Paulo: Moderna, 1998.

FERREIRA, N. S. C. Memorial apresentado e defendido no Concurso para Professor Titular da Universidade Tuiuti do Paraná. Curitiba: UTP, 2002.

FERREIRA, N. S. C. Formação continuada e gestão da educação no contexto da 'cultura globalizada'. In: FERREIRA, N. S. C. Formação humana e gestão da educação. 3. ed. São Paulo: Ed Cortez, 2010. p. 9-39. 
FERREIRA, N. S. C. A gestão da educação e as políticas de formação de profissionais da educação: desafios e compromissos. In: FERREIRA, N. S. C. Gestão democrática da educação: atuais tendências, novos desafios. 8. ed, 3. reimp. São Paulo: Cortez: 2013. p.5-142.

FERREIRA, N. S. C. Supervisão educacional: uma reflexão crítica. 16. ed. revista e atualizada. Petrópolis, RJ: Ed Vozes, 2007.

GIDDENS, A; PIERSON, C. Conversas com Anthony Giddens: o sentido da modernidade. Rio de Janeiro : Ed. FGV, 2000.

MARX, K. Manuscritos Económico-filosófico de 1844. Bogotá: Pluma, 1980.

ONU. Declaração Universal dos Direitos Humanos, de 10 de dezembro de 1948. Adotada e proclamada pela resolução 217 A (III) da Assembléia Geral das Nações Unidas em 10 de dezembro de 1948. Disponível em: <http://www.onu.org.br/ img/2014/09/DUDH.pdf〉. Acesso em: 20 set. 2016.

VAZQUEZ, A. S. Filosofia da Práxis. 2. ed. Rio de Janeiro: Ed. Paz e Terra, 1977.

Recebido: 30/08/2016

Received: 08/30/2016

Aprovado: 18/09/2016 Approved. 09/18/2016 